\title{
CONSUMO, DIGESTIBILIDADE E CURVA GLICÊMICA DE OVELHAS EM FINAL DE GESTAÇÃO RECEBENDO DIFERENTES RELAÇÕES VOLUMOSO:CONCENTRADO
}

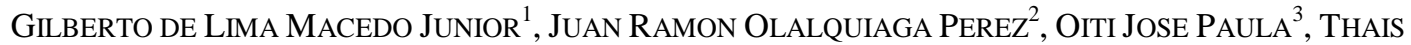 \\ ROMANO VASCONCElos AlmeIDA ${ }^{4}$, ROBERTA MOURA AsSIS ${ }^{5}$, PATRICIA MARIA FranÇA ${ }^{6}$ \\ ${ }^{1}$ Professor Doutor da Universidade Federal de Uberlândia, Uberlândia, MG, Brasil - gilbertomacedojr@gmail.com \\ ${ }^{2}$ Professor Doutor Universidade Federal de Lavras, Lavras, MG, Brasil. \\ ${ }^{3}$ Membro do conselho fiscal do Grupo de Apoio à Ovinocultura, Universidade Federal de Lavras, Lavras, MG, Brasil \\ ${ }^{4}$ Professora do Instituto Federal Fluminense, Campus Bom Jesus do Itabapoana, Bom Jesus do Itabapoana, RJ, Brasil. \\ ${ }^{5}$ Professora Doutora da Universidade Federal de Goiás, Campus Jataí, Jataí, GO, Brasil \\ ${ }^{6}$ Pós-doutoranda da Universidade Federal de Lavras, Lavras, MG, Brasil.
}

RESUMO

\begin{abstract}
O objetivo do presente trabalho foi avaliar a influência de diferentes relações volumoso:concentrado na dieta de ovinos sobre o consumo, glicemia e digestibilidade aparente em fêmeas gestantes. Para isso, foi realizado um ensaio de digestibilidade in vivo, no qual se determinou o consumo e os coeficientes de digestibilidade aparente, e coleta de sangue. Foram utilizadas 16 ovelhas adultas, gestantes da raça Santa Inês, com peso vivo de 54,10 \pm $5,89 \mathrm{~kg}$, distribuídas em delineamento inteiramente casualizado com quatro tratamentos $(10 \% ; 20 \% ; 30 \%$ e
\end{abstract}

$40 \%$ de volumoso). As variáveis referentes ao consumo de MS, ED, EM e PD, bem como os coeficientes de digestibilidade aparente da MS e FDN não foram influenciados pelos tratamentos. O CFDN aumentou com o acréscimo de fibra em detergente neutro de origem forrageira nas dietas e a digestibilidade da PB diminuiu. A concentração de glicose foi afetada de forma significativa tanto em função dos tratamentos como dos horários de colheita.

PALAVRAS-CHAVE: Fibra; glicose; metabolismo; prenhes; rumem.

\section{INTAKE, DIGESTIBILITY AND GLYCEMIC CURVE OF SHEEP IN THE END OF PREGNANCY RECEIVING DIFFERENT ROUGHAGE:CONCENTRATE RELATION}

\section{ABSTRACT}

This research was carried out to investigate the effect of different levels of forage and concentrate in the diet offered to pregnant ewes on the intake, glucose level and apparent digestibility. A study of in vivo digestibility was done to determine the intake and the apparent digestibility and blood samples were collected to determine the glucose concentration. Sixteen adult, pregnant, nonlactating, Santa Inês ewes, weighting $54.10 \pm 5.89 \mathrm{~kg}$, were used. The experimental design used was a

KEYWORDS: Fiber; glucose; metabolism; pregnant; rume. completely randomized arrangement, with four treatments $(10 \% ; 20 \% ; 30 \%$ and $40 \%$ of roughage). The intake of DM, digestible energy, metabolizable energy and digestible protein was not influenced by treatments. The apparent digestibility of DM, CE and neutral detergent fiber (NDF) was not influenced by treatments. The apparent digestibility of CP and the intake of NDF were influenced by treatments. The glucose level was influenced by treatments and the times of collection. 


\section{INTRODUÇÃO}

O uso do perfil metabólico como indicador do estado nutricional e da saúde do rebanho de ruminantes foi proposto na década de 70 por PAYNE et al. (1970). Posteriormente, FOOT et al. (1984) e RUSSEL (1991) sugeriram métodos mais precisos para se conhecer as necessidades nutricionais de ovelhas.

Os constituintes do plasma sanguíneo têm relação direta com a composição química e a digestibilidade dos componentes da dieta. Dessa forma, as diferentes fontes de volumoso e as diferentes relações volumoso:concentrado podem apresentar efeitos sobre a composição do plasma (ARRUDA et al., 2008). Nesse sentido, metabólitos plasmáticos como a glicose vêm sendo estudados como indicadores do estado energético, porém os resultados são contraditórios, conforme cita o NRC (2006).

A glicose no ruminante é oriunda, em grande parte (cerca de 60\%), do ácido propiônico, após conversão no fígado (CALDEIRA, 2005). Assim, dietas que elevam a proporção desse ácido na fermentação ruminal podem elevar a produção de glicose no fígado (NRC, 2006). RIGOLON et al. (2008), trabalhando com vacas, verificaram aumento significativo na glicemia basal com a elevação da ingestão diária de matéria seca.

Sabe-se que o feto in útero demanda glicose como maior fonte de energia. No período posterior ao parto, os níveis caem novamente, especialmente na primeira semana e em animais de alta produção (GONZÁLEZ \& SILVA, 2002). Dessa forma, a gestação provoca alterações na demanda de glicose pela fêmea.

O objetivo deste trabalho foi avaliar a influência das diferentes relações volumoso:concentrado no consumo, glicemia e digestibilidade aparente em ovelhas gestantes no terço final com um feto.

\section{MATERIAL E MÉTODOS}

O experimento foi conduzido no Departamento de Zootecnia, da Universidade Federal de Lavras - UFLA, em julho de 2003. Os animais foram alojados em gaiolas metabólicas individuais, próprias para o ensaio de digestibilidade in vivo, providas de comedouro, bebedouro e cocho próprio para suplementação mineral. As fezes eram recolhidas em bandejas plásticas e a urina acondicionada em baldes plásticos, adaptados com uma tela separadora, evitando-se que as fezes e a urina se misturassem. Cada balde recebeu $100 \mathrm{~mL}$ de ácido sulfúrico $\left(\mathrm{H}_{2} \mathrm{SO}_{4}\right)$ a $2 \mathrm{~N}$ a fim de evitar perdas de nitrogênio. A alimentação dos animais foi constituída de feno de capim coast-cross (Cynodon dactylon L. Pers.) picado, milho moído (Zea mays L.), farelo de soja (Glicine max) e premix mineral (Tabela 1), oferecida em duas refeições diárias (às $8: 00 \mathrm{~h}$ e às $17: 00 \mathrm{~h}$ ), sendo que a primeira refeição continha $60 \%$ do total diário ofertado. As dietas foram balanceadas segundo o NRC (1985), a fim de suprir as necessidades e permitindo uma sobra de 10\% (Tabela 1).

Foram utilizadas 16 ovelhas da raça Santa Inês, prenhas no terço final de gestação, com peso médio e desvio padrão de $54,10 \pm 5,89 \mathrm{~kg}$. Os animais foram sincronizados com uso de hormônios para estarem no mesmo período de gestação no momento das coletas. Aos 60 dias de gestação foi realizado exame de ultrassonografia para detecção do número de fetos. Foram utilizadas somente ovelhas com um feto. As mesmas estavam na segunda ordem de parição. Os tratamentos consistiam de quatro níveis de fibra em detergente neutro de origem forrageira (FDNf), sendo:

Tratamento 10:90: (10\% de volumoso + concentrado e premix mineral.

Tratamento 20:80: (20\% de volumoso) + concentrado e premix mineral.

Tratamento 30:70: (30\% de volumoso) + concentrado e premix mineral.

Tratamento 40:60: (40\% de volumoso) + concentrado e premix mineral.

O período experimental foi composto por uma fase de adaptação e uma de coletas, a primeira teve duração de 15 dias e a segunda de cinco dias.

Foram retiradas amostras do feno e dos diferentes concentrados, diariamente, a fim de se obter a composição bromatológica das dietas experimentais. O alimento recusado (sobra) era coletado individualmente, antes de se oferecer a refeição matutina, sendo pesado e amostrado diariamente. A coleta de fezes era total sendo seu peso anotado e amostrado $20 \%$ do total defecado. As amostras foram acondicionadas em sacos plásticos devidamente identificados e congeladas no freezer a $-20^{\circ} \mathrm{C}$. A urina excretada por cada animal tinha seu volume $(\mathrm{mL})$ registrado, uma amostragem de $10 \%$ do volume total urinado era efetuada e imediatamente colocada em freezer.

Para amostras de fezes, sobras e alimentos foram determinadas: matéria seca (MS), fibra em detergente neutro (FDN), fibra em detergente ácido (FDA), proteína bruta (PB), energia bruta (EB) e cinzas (CI). Nas amostras de urina foram feitas análises de proteína bruta $(\mathrm{PB})$ e energia bruta $(\mathrm{EB})$. As análises químicas foram efetuadas segundo a metodologia descrita por SILVA \& QUEIROZ (2002). 
Os valores de energia metabolizável (EM) foram obtidos através da diferença entre energia digestível e perdas energéticas, advindas da formação de metano e da urina. Para isso usou-se a seguinte fórmula, segundo SNIFFEN et al. (1992):

$\mathrm{EM}=\mathrm{EBI}-(\mathrm{EBF}+\mathrm{EBU}+\mathrm{EPGD})$,

$\mathrm{EPGD}=\mathrm{PGD} \times \mathrm{EBI} / 100$,

$\mathrm{PGD}=4,28+0,059$ CDEB .

Em que: $\mathrm{EM}=$ energia metabolizável; $\mathrm{EBI}=$ energia bruta ingerida; $\mathrm{EBF}=$ energia bruta fecal; $\mathrm{EBU}=$ energia bruta urinária; EPGD = energia perdida de gás na digestão; PGD = perda de gás na digestão; CDEB = coeficiente de digestibilidade da energia bruta

Os valores de digestibilidade aparente (DA) dos nutrientes foram obtidos pela fórmula a seguir, conforme metodologia utilizada por COELHO DA SILVA \& LEÃO (1979):

$$
\mathrm{DA}=\frac{(\mathrm{kgcons} \times \% \text { cons })-(\mathrm{kgsb} \times \mathrm{sb})-(\mathrm{kgfz} \times \% \mathrm{fz})}{(\mathrm{kgcons} \times \% \operatorname{cons})-(\mathrm{kgsb} \times \mathrm{sb})}
$$

Em que: kgcons = quantidade de alimento consumido; $\%$ cons $=$ teor do nutriente no alimento fornecido; $\mathrm{kg} \mathrm{sb}=$ quantidade de sobras retiradas; $\%$ $\mathrm{sb}=$ teor do nutriente nas sobras; $\mathrm{kg} \mathrm{fz}=$ quantidade de fezes coletadas; $\% \mathrm{fz}=$ teor do nutriente nas fezes.

A colheita de sangue procedeu-se aos 145 dias de gestação e em quatro horários distintos: 8 horas (momentos antes de se oferecer a primeira parte da refeição), 11, 14 e 17 horas (antes de fornecer a segunda alimentação). Foram retirados $0,5 \mathrm{~mL}$ de sangue com auxílio de uma seringa, diretamente da veia jugular. Imediatamente após a colheita era colocada uma gota na fita para se obter o valor da glicemia. Este valor foi obtido 45 segundos após o procedimento descrito, através do monitor de glicemia ACCU CHEK da Roche. O resultado foi obtido em $(\mathrm{mg} / \mathrm{dL})$.

$\mathrm{O}$ delineamento experimental utilizado foi inteiramente casualizado com quatro repetições por tratamento, sendo cada animal uma unidade experimental.

TABELA 1. Composição bromatológica, centesimal e proporção dos ingredientes das dietas.

\begin{tabular}{|c|c|c|c|c|c|c|}
\hline & $10: 90$ & \multicolumn{2}{|l|}{$20: 80$} & \multirow{2}{*}{\multicolumn{2}{|c|}{$30: 70$}} & $0: 60$ \\
\hline \multicolumn{5}{|c|}{ Composição bromatológica } & & \\
\hline MS \% & 83,44 & 83,10 & & 82,49 & & \\
\hline FDN \% & 8,67 & 17,34 & & 26,01 & & \\
\hline FDA \% & 10,92 & 15,99 & & 32,35 & & \\
\hline $\mathrm{PB} \%$ & 19,59 & 20,47 & & 20,61 & & \\
\hline CINZAS \% & 4,41 & 4,49 & & 4,60 & & \\
\hline $\mathrm{MO} \%$ & 95,59 & 95,51 & & 95,40 & & \\
\hline $\mathrm{EM} \mathrm{kcal} / \mathrm{g}^{2}$ & 2.954 & 2.948 & & 2.945 & & \\
\hline \multicolumn{7}{|c|}{ Proporção dos ingredientes (\%) } \\
\hline Feno & 10,00 & 20,00 & & 30,00 & \multicolumn{2}{|c|}{40,00} \\
\hline Milho & 66,50 & 56,50 & & 46,50 & \multicolumn{2}{|c|}{37,50} \\
\hline F de soja & 22,50 & 22,50 & & 22,50 & \multicolumn{2}{|c|}{22,50} \\
\hline Premix $^{1}$ & 1,0 & 1,0 & & 1,0 & \multicolumn{2}{|c|}{1,0} \\
\hline & MS (\%) & PB (\%) & $\mathrm{FDN}(\%)$ & FDA $(\%)$ & $\mathrm{Ca}(\%)$ & $\mathrm{P}(\%)$ \\
\hline \multicolumn{7}{|l|}{ Ingredientes } \\
\hline Feno de Coast-cross & 91,30 & 8,53 & 78,63 & 33,93 & 0,733 & 0,434 \\
\hline Milho grão & 86,77 & 10,56 & 21,58 & 4,03 & 0,063 & 0,311 \\
\hline Farelo de Soja & 88,40 & 45,62 & 20,70 & 10,17 & 0,452 & 0,781 \\
\hline Calcário calcítico & 99,99 & - & - & - & 35,84 & - \\
\hline Sal comum & 99,82 & - & - & - & - & - \\
\hline Premix ${ }^{1}$ & 94,36 & - & - & - & 23,00 & 9,00 \\
\hline
\end{tabular}

\footnotetext{
${ }^{1}$ Nutrientes/kg de suplemento: Cálcio $=230$ g; Fósforo = 90 g; Enxofre = 15 g; Magnésio = 20 g; Sódio = 48 g; Cobalto = 100 mg; Cobre $=700 \mathrm{mg}$; Ferro = $2.000 \mathrm{mg}$; Iodo $=80 \mathrm{mg}$; Manganês $=1250 \mathrm{mg}$; Selênio $=200 \mathrm{mg} ;$ Zinco $=2.700 \mathrm{mg} ;$ Flúor $=900 \mathrm{mg}$; Vitamina A $=200.000$ UI; Vitamina D3 = 60.000 UI; Vitamina $E=60$ UI. ${ }^{2}$ Valor obtido pela fórmula de SNIFFEN et al. (1992). Matéria seca (MS), Fibra em Detergente Neutro (FDN), Fibra em Detergente Ácido (FDA), Proteína Bruta (PB), Matéria Orgânica (MO) e Energia Metabolizável (EM).
} 


\section{RESULTADOS E DISCUSSÃO}

Observando as Figuras 1 e 2, verifica-se que somente o consumo de fibra em detergente neutro e a digestibilidade aparente da proteína bruta foram afetados significativamente pelas dietas experimentais $(\mathrm{P}<0,05)$. $\mathrm{O}$ consumo de matéria seca não foi influenciado pelos tratamentos. $\mathrm{O}$ fato de a ovelha estar no terço final de gestação, fase em que o útero gravídico está comprimindo o trato gastrintestinal, pode ter afetado significativamente o consumo dos animais, além do que as dietas possuíam alta densidade energética que pode também afetar o consumo pelos animais. Vários trabalhos (PEREZ et al., 2001; PEDROSO et al., 2004a; PEDROSO et al., 2004b; MACEDO JUNIOR et al., 2006a) têm mostrado a depressão no consumo quando grande quantidade de carboidratos solúveis é utilizada nas dietas. VAN SOEST (1994) afirma que a saciedade se deve à densidade calórica da dieta. Pelo NRC (1985), em dietas que possuem mais de $70 \%$ de concentrado, o consumo de forragens é insuficiente para fermentação ruminal normal. MACEDO JUNIOR et al (2006b), trabalhando com ovelhas não gestantes e com as mesmas proporções de volumoso e concentrado deste experimento, observaram maior consumo na medida em que se aumentavam os níveis de volumoso nas dietas experimentais. Pelo NRC (1985), em ovelhas nas últimas quatro semanas de gestação com $60 \mathrm{~kg}$ de peso vivo, o consumo de
MS deve ser de $1,6 \mathrm{Kg}$ ou $2,8 \%$ do peso vivo. No presente estudo, o consumo médio de matéria seca foi de $1,64 \mathrm{~kg}$ ou $3,03 \%$ do peso vivo, mostrando que os resultados estão dentro do preconizado por esse comitê.

$\mathrm{O}$ consumo de proteína digestível não foi influenciado pelos tratamentos $(\mathrm{P}>0,05)$. Esse resultado pode ser explicado pelo fato de que as dietas eram isonitrogenadas e não houve diferença significativa $(\mathrm{P}>0,05)$ no consumo de matéria seca. O consumo de energia digestível e metabolizável não foi afetado pelos tratamentos. Pelo NRC (1985), em ovelhas nessas condições, o consumo esperado de energia metabolizável é de 3600 kcal. Neste estudo, o consumo médio de energia metabolizável foi de 4463,08 kcal, apresentando-se acima do recomendado pelo NRC (1985). MACEDO JUNIOR et al, (2006b), trabalhando com ovelhas não gestantes e com as mesmas proporções de volumoso e concentrado deste experimento, verificaram incremento no consumo de energia metabolizável na medida em que se aumentou o nível de volumoso nas dietas. Os autores afirmam que esse resultado ocorreu em função da melhor condição de fermentação ruminal provocada pela inclusão de fibra na dieta. No presente estudo, a igualdade no consumo de matéria seca pode ter contribuído para que não houvesse diferença estatística no consumo dos demais nutrientes até aqui discutidos. Na Tabela 2 são mostradas as médias das variáveis estudadas.

TABELA 2. Consumo e digestibilidade de nutrientes em função do nível de concentrado na dieta em ovelhas no terço final de gestação

\begin{tabular}{cccccc}
\hline Variáveis & $10: 90$ & $20: 80$ & $30: 70$ & $40: 60$ & CV $(\%)$ \\
\hline CMS & 78,30 & 66,33 & 80,47 & 78,78 & 21,84 \\
CFDN $^{*}$ & 22,43 & 23,53 & 32,64 & 34,37 & 19,81 \\
CED & 240,16 & 203,64 & 244,66 & 238,79 & 22,30 \\
CEM & 216,05 & 178,39 & 220,89 & 211,85 & 23,47 \\
CPD & 10,57 & 9,29 & 8,54 & 9,46 & 27,94 \\
DMS & 71,03 & 75,58 & 69,96 & 68,86 & 6,29 \\
DEB & 70,04 & 71,50 & 69,66 & 69,10 & 6,50 \\
DPB & 69,25 & 68,50 & 52,75 & 54,50 & 11,80 \\
DFDN & 51,25 & 56,25 & 55,75 & 56,25 & 13,74 \\
\hline
\end{tabular}

*Significativo a $(\mathrm{P}<0,05 \%)$. As médias aqui apresentadas são para facilitar a visualização dos dados. Consumo médio de matéria seca (CMS), fibra em detergente neutro (CFDN), energia digestível (CED), energia metabolizável (CEM) e proteína digestível (CPD) expressos em g/kg,75 e kcal/kg ${ }^{0,75}$, coeficiente de digestibilidade da matéria seca (DMS), energia bruta (DEB), proteína bruta (DPB) e fibra em detergente neutro (DFN) expressos em $\%{ }^{*} \mathrm{Y}=0,4493 \mathrm{X}+17,01\left(\mathrm{R}^{2} 89,42 \%\right),{ }^{* *} \mathrm{Y}=-0,6000 \mathrm{X}+76,25\left(\mathrm{R}^{2}=76,80 \%\right)$

O consumo de fibra em detergente neutro aumentou significativamente $(\mathrm{P}<0,05)$ com $\mathrm{o}$ acréscimo de volumoso (Figura 1), verificando-se efeito linear dos níveis de volumoso sobre o consumo de FDN. MACEDO JUNIOR et al. (2006 b) observaram efeito linear sobre o consumo de FDN na medida em que se elevou a quantidade de volumoso na dieta. No presente estudo, o consumo 
de FDN foi de $34,37 \mathrm{~g} / \mathrm{kg}^{0,75}$, na dieta com $40 \%$ de volumoso. MACEDO JUNIOR et al. (2006b), trabalhando com ovelhas não gestantes e com as mesmas proporções de volumoso e concentrado desse experimento, verificaram que o consumo de FDN foi de $33,35 \mathrm{~g} / \mathrm{kg}^{0,75}$ também com $40 \%$ de volumoso na dieta. A figura 1 mostra o CFDN em $\mathrm{g} / \mathrm{kg}^{0,75} \mathrm{em}$ função dos tratamentos.

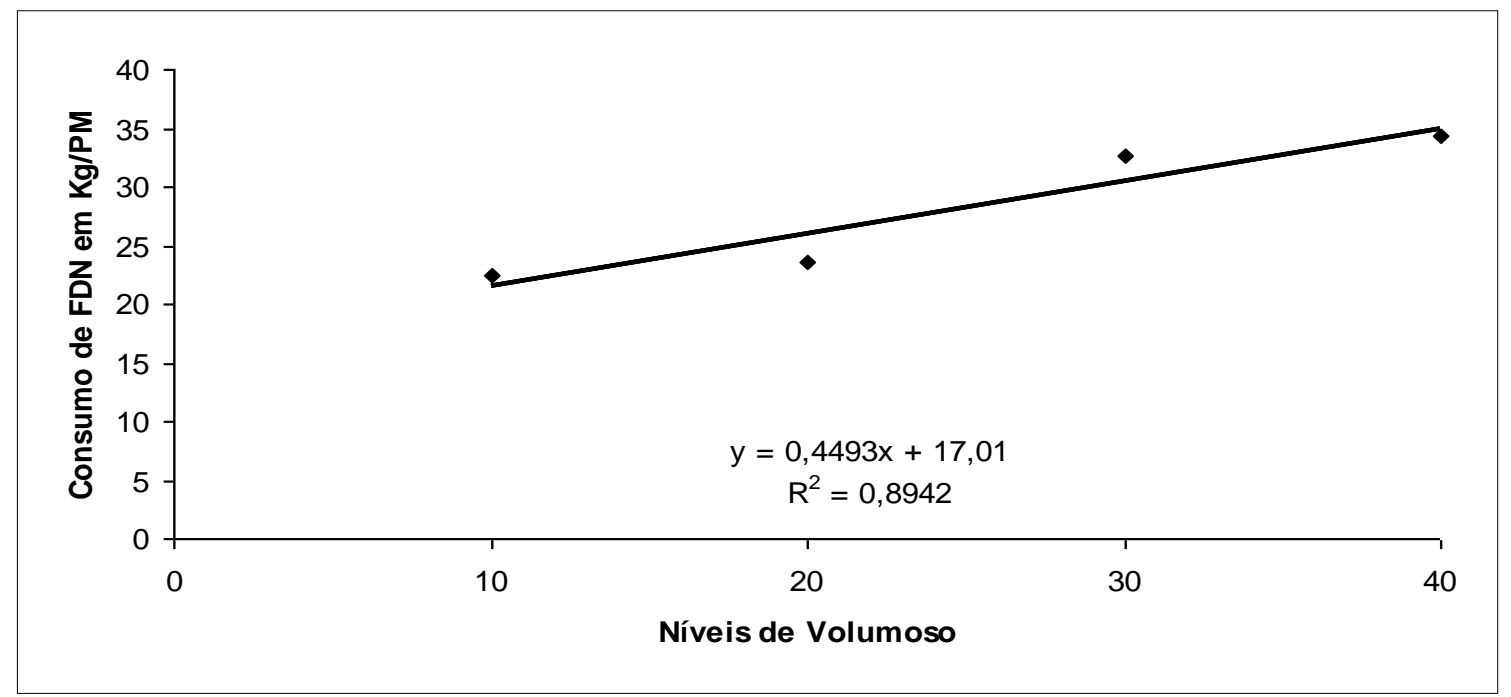

Figura 1. Consumo de fibra em detergente neutro $\left(\mathrm{g} / \mathrm{kg}^{0,75}\right)$ em função do nível de volumoso dietético.

A digestibilidade da matéria seca não foi influenciada pelos níveis de volumoso das dietas experimentais. MACEDO JUNIOR et al., (2006 b), trabalhando com ovelhas não gestantes e com as mesmas proporções de volumoso e concentrado deste experimento, observaram aumento na digestibilidade da MS com a inclusão de volumoso nas dietas. Outro motivo que pode ser especulado como fator de igualdade na DMS foi o fato de a ovelha estar no final da gestação, fase que produz grandes mudanças nas exigências nutricionais e na capacidade digestiva das ovelhas (NRC, 1985; NRC, 2006). ALVES et al. (2003), trabalhando com diferentes níveis de energia metabolizável $(2,42 ; 2,66$; e $2,83 \mathrm{Mcal} / \mathrm{kg}$ de MS), observaram crescimento linear na digestibilidade da MS na medida em que se elevou o nível de energia das dietas. Avaliando o efeito da frequência da suplementação com concentrado sobre a digestibilidade aparente dos nutrientes, CASTRO et al. (2002) observaram que o aumento da frequência de suplementação não afetou essas variáveis.

A digestibilidade da PB foi influenciada pelos níveis de FDNf, apresentando comportamento linear (Figura 2), isto é, na medida em que se diminuiu a quantidade de volumoso da dieta, elevou-se a digestibilidade, provavelmente influenciada pela maior quantidade grãos na dieta. Carboidratos não estruturais possuem coeficiente de digestibilidade aparente total acima de $90 \%$ e carboidratos estruturais próximos a 50\% (ZANINE \& MACEDO JUNIOR, 2006). BERCHIELLE et al. (2006) afirmaram que a qualidade do volumoso, a forma de apresentação e a quantidade de carboidratos solúveis podem interferir na DMS.

MACEDO JUNIOR et al. (2006b), trabalhando com ovelhas não gestantes e com as mesmas proporções de volumoso e concentrado deste experimento, encontraram resultado inverso, isto é, na medida em que se elevou a quantidade de volumoso, elevou-se o coeficiente de digestibilidade da PB. No presente estudo, os tratamentos não influenciaram a DFDN, o mesmo ocorrendo com MACEDO JUNIOR et al. (2006b) com o aumento nos níveis de FDNf das dietas. A Figura 2 mostra a digestibilidade da proteína bruta em função dos níveis de volumoso. 


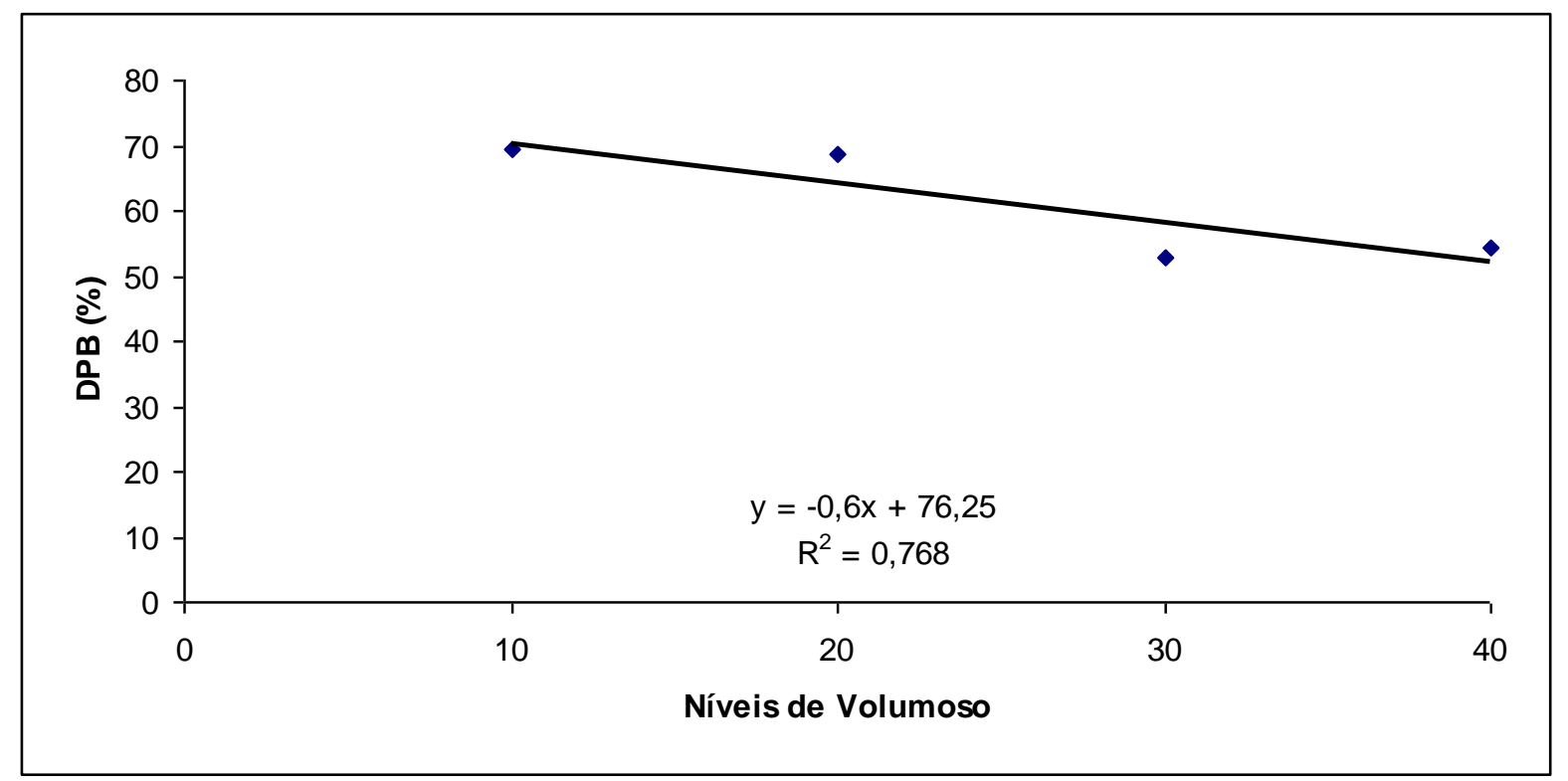

Figura 2. Digestibilidade da proteína bruta (\%) em função do nível de volumoso da dieta.

Nas Figuras 3 e 4 encontram-se os resultados da glicemia dos animais estudados. Conforme mostra a Figura 3, as concentrações de glicose foram afetadas de forma significativa pelos níveis de FDNf. O tratamento 20:80 apresenta o maior valor de glicemia, indicando que essa dieta possivelmente propiciou maior aproveitamento dos nutrientes, elevando, consequentemente, a glicemia dos animais (Figura 3). Essa dieta continha $80 \%$ de concentrado e $20 \%$ de volumoso. Essa quantidade de carboidrato solúvel possivelmente elevou a glicemia desses animais, pois esse tipo de carboidrato aumenta a produção de propionato, que é precursor de glicose no fígado.

O metabolismo energético em ruminantes é muito complexo. Os carboidratos solúveis ingeridos são facilmente fermentados pelos microorganismos no rumem. Os produtos finais da fermentação dos carboidratos são os ácidos graxos voláteis (AGVs). Um aporte elevado de carboidrato solúvel na dieta leva a incremento na produção de ácido propiônico, que é o único dos AGVs precursor de glicose no ruminante. Assim, podemos inferir que a alta proporção de grãos na dieta do tratamento 20:80 deste experimento levou ao aumento na glicemia dos animais.

Ao observar a Figura 2, verifica-se que o tratamento 20:80 apresentou melhor digestibilidade da proteína, assim podemos inferir que esse resultado possa ter elevado a glicemia basal, uma vez que parte da glicose formada nos ruminantes vem de aminoácidos glicogênicos. HUNTINGTON (1997) verificou aumento substancial nos níveis de glicose em vacas de corte e de leite consumindo alta quantidade de carboidrato solúvel e que $30 \%$ da glicose requerida são provenientes da dieta, $50 \%$ da gliconeogênese e $20 \%$ de outras fontes. NUNES et al. (2002), trabalhando com cabras Saanen em lactação em dois regimes de fornecimento de concentrado e dois sistemas de produção, observaram que o aumento no consumo de concentrado elevou os níveis de glicose (obtendo média de $54,74 \mathrm{mg} / 100 \mathrm{~mL}$ ) em função da maior disponibilidade de carboidrato solúvel. Podemos observar que no presente estudo os valores de glicemia foram mais altos (média de $59,54 \mathrm{mg} / \mathrm{dL}$ ), possivelmente influenciados pelo alto consumo de energia metabolizável, que se apresentou bem acima do recomendado pelo NRC (1985). KANEKO (1997) afirmam que os valores de referência para ovinos variam de $50-80 \mathrm{mg} / \mathrm{dL}$, mostrando que os valores deste experimento estão dentro dessa faixa de concentração.

Vários fatores afetam o nível plasmático de glicose em ruminantes, o que torna difícil a sua compreensão. Dentre eles, destacam-se qualidade da dieta, proporção de volumoso e concentrado, natureza química do carboidrato, produção de leite, temperatura, condição fisiológica (gestante, em lactação, vazias etc), entre outros fatores (ZANINE \& MACEDO JUNIOR, 2006). Nesse sentido, RIBEIRO et al. (2004), trabalhando com ovelhas Border Leicester cruzadas com ovelhas Texel, verificaram queda na glicemia das mesmas ao final da gestação quando comparadas com o início da prenhez. 
O fato de o tratamento 10:90 ter apresentado valor mais baixo na concentração de glicose (Figura 3) pode ser em função de algum tipo de distúrbio metabólico, como a acidose subclínica, já que não houve diferença significativa no consumo de matéria seca e, durante o experimento, foi observado comportamento irregular no consumo pelos animais desse tratamento, fato esse que vem reforçar essa suposição.

O tratamento 40:60 também apresentou menor valor na concentração de glicose, porém esse resultado pode ser explicado pelo menor aporte energético dessa dieta. A maior quantidade forrageira desse tratamento possivelmente promoveu aumento na produção de ácido acético em relação ao propiônico, uma vez que, segundo VAN SOEST (1994), dietas ricas em forragem apresentam maior proporção molar de ácido acético. Na Figura 3 encontra-se o comportamento da glicemia em função dos níveis de volumoso nas dietas.

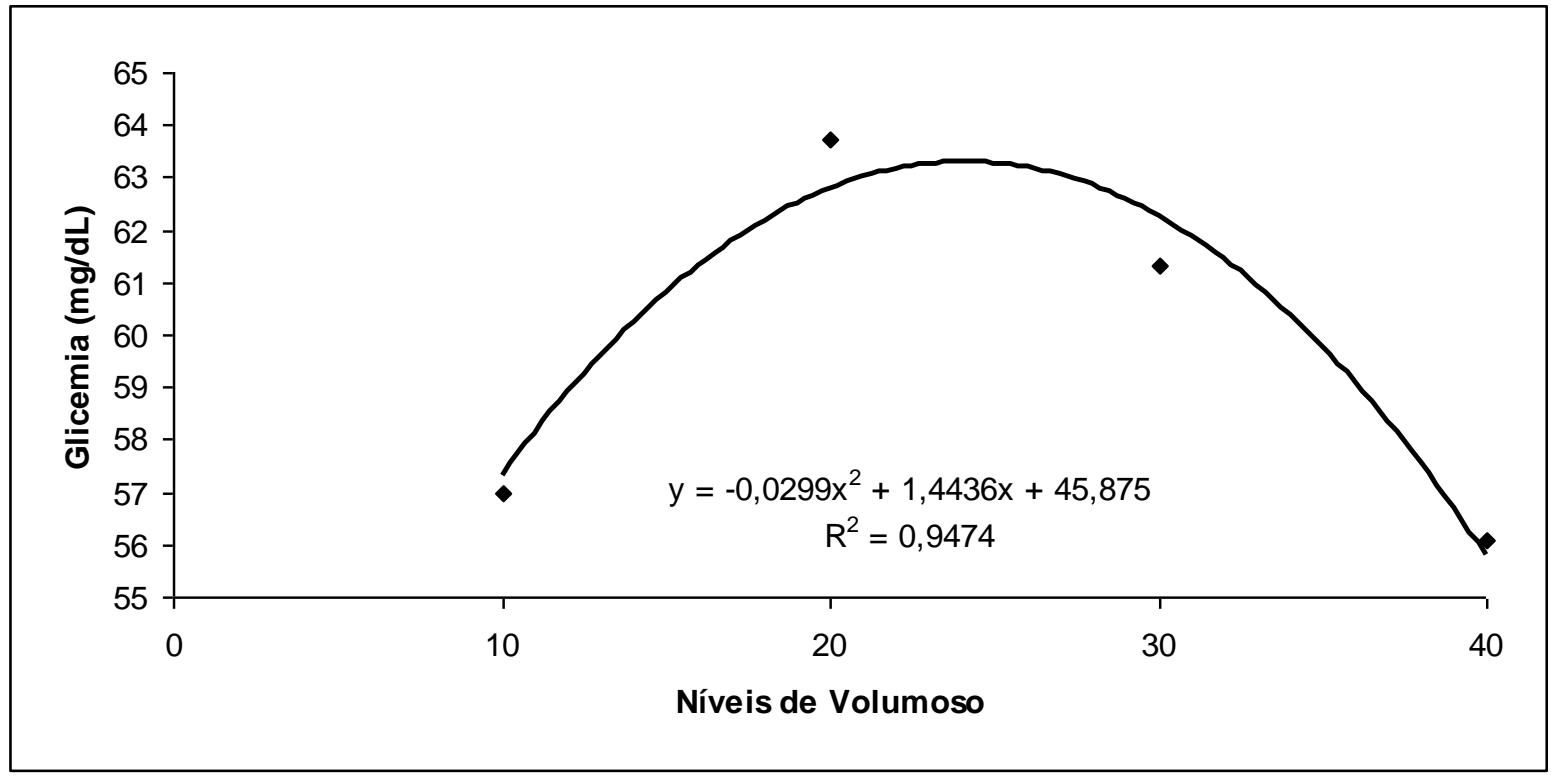

Figura 3 - Valores de glicemia (mg/dL) em função do nível de volumoso da dieta.

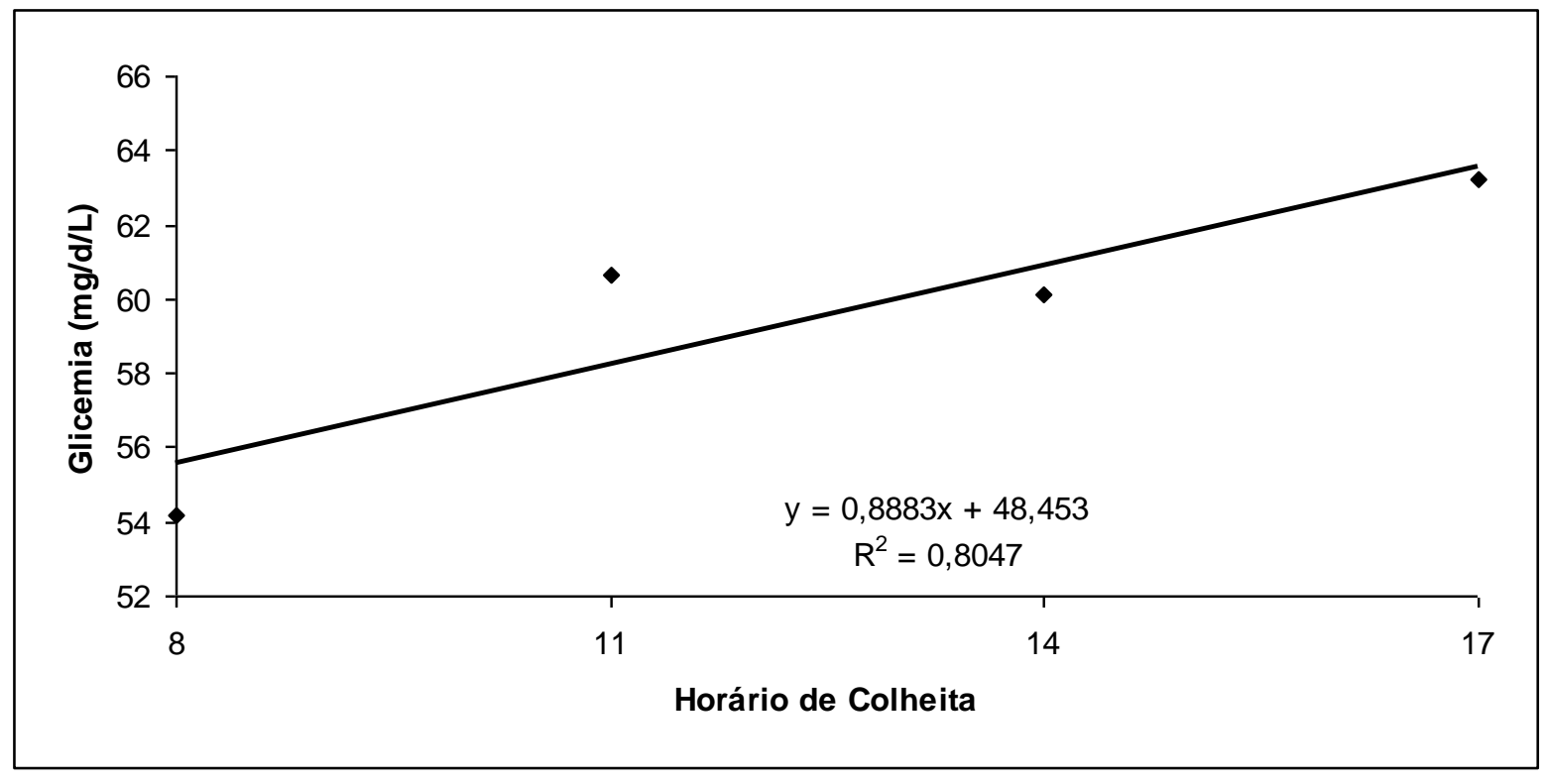

Figura 4. Valores de glicemia basal em função dos horários de colheita. 
Na Figura 4 pode-se observar que ocorre influência significativa na concentração de glicose em função dos horários de colheita. A equação de regressão dessa variável assumiu comportamento linear. No primeiro horário de colheita de sangue a concentração de glicose foi menor que nos demais horários (Figura 4). Segundo CALDEIRA (2005), em ruminantes, o pico na concentração de glicose ocorre de $3-6$ horas após a alimentação, pois a glicose para esses animais depende da síntese no fígado a partir de propionato, aminoácidos glicogênicos e outros precursores. No presente estudo, observou-se claramente esse comportamento.

\section{CONCLUSÃO}

A glicemia basal de ovelhas gestantes é sensível à composição da dieta, evidenciando que a relação volumoso:concentrado pode alterar o status energético do animal. $\mathrm{O}$ fato de as ovelhas estarem gestantes parece ter comprometido a ingestão de matéria seca e das demais variáveis estudadas. Contudo, a glicemia manteve-se dentro dos valores normais para a espécie.

\section{REFERÊNCIAS}

ALVES, K. S.; CARVALHO, F. F. R.; VERAS, A. S. C.; FERREIRA, M. A.; COSTA, R. G.; SANTOS, E. P.; FREITAS, C. R. G.; SANTOS JUNIOR, C. M.; ANDRADE, D. K. B. Níveis de energia em dietas para ovinos Santa Inês: Digestibilidade Aparente. Revista Brasileira de Zootecnia, v. 32, n. 6, p. 1962-1968, 2003.

ARRUDA, D. S. R.; CALIXTO JUNIOR, M.; JOBIM, C. C.; SANTOS, G. T. Efeito de diferentes volumosos sobre os constituintes sangǘneos de vacas da raça holandesa. Revista Brasileira de Saúde e Produção Animal, v. 9, n.1, p.35-44, 2008.

BERCHIELLE, T. T., PIRES, V. P., OLIVEIRA, S. G. Nutrição de ruminantes, Jaboticabal: Funep, 2006. 583p.

CALDEIRA, R. M. Monitorização da adequação do plano alimentar e do estado nutricional em ovelhas. Revista Portuguesa de Ciências Veterinárias, v. 100. n. 555-556 p. 125-139, 2005.

CASTRO, T.; MANSO, T.; MANTECÓN, A. R. Effect of either once or twice daily concentrate supplementation of wheat straw on voluntary intake and digestion in sheep. Small Ruminant Research, v. 46, p. 43-50, 2002.

COELHO DA SILVA, J. F.; LEÃO, M. I. Fundamentos da nutrição dos ruminantes. Piracicaba: Livroceres, 1979. 380p.

FOOT, J. S., CUMMINS, L. J., SPIKER, S. A., FLINN, P. C. Concentration of beta-hydroxybutyrate in plasma of ewe in late pregnancy and early lactation, and survival and growth of lambs. In: Reproduction in sheep. Ed. Lindsay, D.R. \& Pearce, D.T. Australian Academy of Science: Camberra, 1984. p.187-190.

GONZÁLEZ, F. H. D.; SILVA, S. C. Introdução à bioquímica clínica animal. Porto Alegre: Gráfica da Universidade Federal do rio Grande do Sul, 2002.198p.

HUNTINGTON, G. B. Starch utilization by ruminants. From basics to the brink. Journal of Animal Science, v. 75, n. 3, p. 852-867, 1997.

KANEKO, J. J. Clinical Biochemistry of Domestic Animals. 5ed. Academic Press: New York, 1997. 932p.

MACEDO JUNIOR, G. L., PEREZ, J. R. O., ZANINE, A. M., BORGES, I. Qualidade da fibra para a dieta de ruminantes. Ciência Animal, v. 17, n. 1, p. 718, 2006 (a).

MACEDO JÚNIOR, G. 1.; PEREZ, J.R.O.; PAULA, O. J.; FRANÇA, P. M.; ASSIS, R. M.; ALMEIDA, T. R. V. Influência de diferentes níveis de FDN dietético no consumo e digestibilidade aparente de ovelhas Santa Inês. Ciência e Agrotecnologia, v. 30, n. 3, p.547-553, Maio/Junho, 2006 (b).

NATIONAL RESEARCH COUNCIL. Nutrient requirement of sheep. $6^{\text {th }}$. ed. Washington: National Academy, 1985. 99p.

NATIONAL RESEARCH COUNCIL - Nutrient Requirements of small ruminants: sheep, goats, cervids and new camelids. Washington: National Academic Press, 2006. 362p.

NUNES, A. S.; BARBOSA, O. R.; SAKAGUTI, E. S.; SAKUNO, M. L. K.; ARAUJO, M. F. T. E.; SILVA, C. P.; Efeito de Dois Regimes de Suplementação Alimentar e Dois Sistemas de Produção, nos Constituintes Sangüíneos de Cabras Saanen Durante a Lactação. Revista Brasileira de Zootecnia, v. 31, n. 3, p. 1245-1250, 2002.

PAYNE, J. M., SALLY, M., MANSTON, R., FAULKS, M. The use of metabolic profile test in dairy herds. Veterinary Record, v. 87, p. 150-158, 1970.

PEDROSO, C. E. S, MEDEIROS, R. B, SILVA, M. A, JORNADA, J. B. J, SAIBRO, J. C, TEIXEIRA, J. R. F. Produção de Ovinos em Gestação e Lactação sob Pastejo em Diferentes Estádios Fenológicos de Azevém Anual. Revista Brasileira de Zootecnia, v. 33, n. 5, p. 13451350, 2004(a).

PEDROSO, C. E. S., MEDEIROS, R. B., SILVA, M. A., JORNADA, B. J., SAIBRO. J. C., TEIXEIRA, J. R. F. Comportamento de Ovinos em Gestação e Lactação sob Pastejo em Diferentes Estádios Fenológicos de Azevém Anual. Revista Brasileira de Zootecnia, v. 33, n. 5, p. 1340-1344, 2004(b).

PÉREZ, J. R. O, GERASEEV, L. C, SANTOS, C. L, TEIXEIRA, J. C, BONAGURIO, S. Composição corporal e exigências nutricionais de cálcio e fósforo de cordeiros Santa Inês em crescimento. Pesquisa Agropecuária Brasileira, v. 36, n. 5, p. 815-822, 2001.

RIBEIRO, L. A. O.; MATTOS, R. C.; GONZALEZ, F. H. 
D.; WALD, V. B.; SILVA, M. A.; LA ROSA, L. V. Perfil metabólico de ovelhas Border Leicester x Texel durante a gestação e lactação. Revista Portuguesa de Ciências Veterinárias, v. 99, n. 551, p. 155-159, 2004.

RIGOLON, L. P.; PRADO, I. N.; CAVALIERI, F. L. B.; NEGRÃO, J. A.; SILVA, R. R.; MARQUES, J. A. Níveis de ingestão de matéria seca sobre metabólitos e hormônios circulantes e hormônios foliculares em novilhas de corte. Revista. Brasileira de Saúde e Produção Animal, v. 9, n. 2, p. 367-383, abr/jun, 2008.

RUSSEL, A. J. F. Nutrition of the pregnant ewe. In : Sheep and goat practice. Editor E. Boden. Baillière Tindall (London), 1991. p. 29-39.

SAEG. Sistemas para análise estatística e genética, versão 9.0. Viçosa, Fundação Arthur Bernardes, 2007.

SILVA, D. J.; QUEIROZ, A. C. Análise de alimentos (métodos químicos e biológicos). 3.ed. Viçosa: UFV, 2002.

SNIFFEN, C.J.; O'CONNOR, J.D.; Van SOEST, P.J.; FOX, D.G.; RUSSEL, J.B.; . A net carbohydrate and protein system for evaluating cattle diets. II. Carbohydrate and protein availability. Journal of Animal Science, v.70, n.11, p.3562-3577, 1992.

VAN SOEST, P. J. Nutritional ecology of the ruminant. 2.ed. Ithaca: Comstock, 1994. 476p.

ZANINE, A.; MACEDO JÚNIOR, G. Importância do consumo da fibra para nutrição de ruminantes. Revista Eletrônica de Veterinária REDVET, v. 7, n. 2, 2006 Disponível

em http://www.veterinaria.org/revistas/redvet/n020207/02071 8.pdf, acessado em março 2012.

Protocolado em: 22 nov. 2010 Aceito em: 09 abr. 2012 